\title{
Research in Mathematics Education
}

Vol. 10, No. 1, March 2008, 97-98

\section{CURRENT REPORT}

\section{Contexts for 'pure' mathematics: a framework for analysing A-level mathematics papers}

Chris Little* and Keith Jones

University of Southampton,UK. c.t.little@soton.ac.uk; d.k.jones@ soton.ac.uk

The use of context in mathematics test items is now accepted practice in many forms of national assessment in the UK. Yet research suggests that such use of context is not straightforward and that children may apply a variety of interpretations to contextual mathematics problems (Boaler 1994; Cooper and Dunne 2000). This raises questions concerning the nature and degree of 'realism' of the selected context and the influence the context might have on the range of responses obtained. In surveying the literature, no research appears to have been carried out on this issue in relation to post-16 examinations.

Our analysis focuses on the use of context in post-16 'pure' mathematics questions set by two UK Examination Boards (Edexcel 2004, OCR 2004), building on research by Vappula and Clausen-May (2006). Using a grounded theory approach (Glaser \& Strauss 1967), six test items from each specification were analysed, and re-analysed, to identify categories and relationships (for more details, see Little and Jones 2007). From the analysis of these questions, a framework for analysing the use of context is proposed.

The first component of the framework is the accessibility of the context, an aspect related to the use of cultural constructs, some of which, by our analysis, appear to be assumed by the Examination Boards to be familiar to all students in UK society (for example, financial constructs such as profit and loss) while others (such as radioactive decay) are assumed to less familiar to some students, with a consequent need for explanatory text. The second component relates to the extent to which the context appears realistic in modelling experience of the real world, whilst at the same time fulfilling the requirement to test specific mathematics. Third, there is the authenticity of the context, in the sense of whether the question tests purely mathematical content, or whether through the item context something is added to knowledge of the context itself. Follow-up research is testing the robustness of the analytic framework and examining how the choice of context relates to the mathematics being tested.

*Corresponding author. Email: c.t.little@ soton.ac.uk 


\section{References}

Cooper, B. and M. Dunne. 2000. Assessing children's mathematical knowledge. Buckingham: OUP.

Boaler, J. 1994. When do girls prefer football to fashion? An analysis of female under-achievement in relation to realistic mathematics contexts. British Educational Research Journal, 20, 551-564.

Edexcel. 2004. C1-4 Specimen papers. London: Edexcel.

Glaser, B. and A. L. Strauss. 1967. The discovery of grounded theory. Chicago: Aldine.

Little, C. and K. Jones. 2007. Contexts for pure mathematics: an analysis of A-level mathematics papers. Proceedings of the British Society for Research into Learning Mathematics 27(1), 48-53.

OCR. 2004. Specimen papers (MEI). Cambridge: OCR.

Vappula, H. and T. Clausen-May. 2006. Context in maths test questions: does it make a difference? Research in Mathematics Education 8, 99-115. 